Madrygal. Revista de Estudios Gallegos

ISSN: 1138-9664

\title{
Nostalgia en clave positiva y perspectiva feminista: la Segunda República como hoja de ruta en Tres tiempos y la esperanza
}

\author{
John Patrick Thompson ${ }^{1}$
}

Recibido: 6 de agosto de 2017 / Aceptado: 21 de setembro de 2017

Resumen. Este artículo analiza dos componentes nodulares del proyecto ideológico de la novela autobiográfica de María Victoria Valenzuela, Tres tiempos y la esperanza (1962), que narra las experiencias de la autora en la Segunda República, la Guerra Civil y el franquismo. Se centra en el papel de la nostalgia que, en la primera parte de la obra, tiñe tanto las descripciones de los recuerdos individuales como los comentarios sobre los hitos del período republicano. La nostalgia se suele relacionar con el esencialismo y lo irracional, pero en esta novela puede inspirar en los lectores empatía hacia los que defendieron la democracia. Después, se examina la perspectiva feminista de la narración que, por una parte, destaca la violencia fascista contra las mujeres y, por otra, rechaza cualquier esencialismo que defienda la existencia de diferencias innatas entre las mujeres y los hombres. Las distinciones que pueda haber entre los dos sexos se retratan como consecuencias de la socialización. Reivindicamos esta novela, casi totalmente olvidada por la crítica, por su valor testimonial y su contenido ético y político. Al contrario de muchas novelas que trivializan el pasado y usan la guerra civil como telón de fondo, la labor memorialista de esta obra recrea una historia libre de las falacias fascistas, que hasta hoy siguen apuntalando la versión hegemónica de los eventos.

Palabras clave: Memoria histórica; Segunda República; franquismo; Guerra Civil; ficción narrativa; testimonio; trauma.

\section{[gl] Nostalxia en clave positiva e perspectiva feminista: a Segunda República como folla de ruta en Tres tiempos y la esperanza}

Resumo. Este artigo analiza dous compoñentes basilares do proxecto ideolóxico da novela autobiográfica de María Victoria Valenzuela, Tres tiempos y la esperanza (1962), que narra as experiencias da autora na Segunda República, a Guerra Civil e o franquismo. Céntrase no papel da nostalxia que, na primeira parte da obra, tingue tanto as descricións das lembranzas individuais canto os comentarios sobre os fitos do período republicano. A nostalxia tende a se relacionar co esencialismo e o irracional, mais nesta novela pode inspirar nos lectores empatía cara aos que defenderon a democracia. Segundo, examínase a perspectiva feminista da narración que, por unha banda, salienta a violencia fascista contra as mulleres e, por outra, rexeita calquera esencialismo que defenda a existencia de diferenzas innatas entre as mulleres e os homes. As distincións que poida haber entre os dous sexos retrátanse como consecuencias da socialización. Reivindicamos esta novela, case totalmente esquecida pola crítica, polo seu valor testemuñal e o seu contido ético e político. Ao contrario de moitas novelas que banalizan o pasado e usan a Guerra Civil como pano de fondo, o labor memorialista desta obra recrea unha historia libre das falacias fascistas, que até hoxe seguen a alicerzar a versión hexemónica dos eventos.

Palabras chave: Memoria histórica; Segunda República; franquismo; Guerra Civil; ficción narrativa; testemuño; trauma.

\section{[en] Positive Nostalgia and a Feminist Perspective: the Spanish Second Republic as a Roadmap in Tres tiempos y la esperanza}

Abstract. This article analyzes two essential components of María Victoria Valenzuela's autobiographical novel entitled Tres tiempos y la esperanza (1962), which narrates the author's experiences during the Spanish Second Republic, the Civil War, and the Franco dictatorship. I focus on the role played by nostalgia which, in the first part of the narrative, colors the descriptions of individual memories, as well as the narrator's comments on the milestones of the Republican period. Nostalgia is usually associated with essentialism and the irrational, but in this novel it can inspire in the reader empathy toward those who defended democracy. I then examine the narrative's feminist perspective

1 Montana State University, Department of Modern Languages \& Literatures.

E-mail: john.thompson166@gmail.com 
that, on the one hand, highlights fascist violence against women. On the other, it rejects any form of essentialism that endorses the existence of innate differences between men and women. Any distinctions between the sexes are portrayed as consequences of socialization. I uphold this novel, almost completely forgotten by the critics, because of its testimonial value and its ethical and political content. Contrary to many novels that trivialize the past and use the Spanish Civil War as a backdrop, this text's commemorative task recreates a history free of the fascist fallacies, which continue to underpin the hegemonic version of the events.

Keywords: Trauma; Narrative Fiction; the Spanish Civil War; the Spanish Second Republic, Historical Memory; Francoism.

Sumario. 1. Introducción. 2. Una crítica negativa de la narrativa guerracivilista contemporánea. 3. De memoria comunicativa a memoria cultural. 4. Nostalgia. 5. La nostalgia intensificada por el trauma y la desesperación. 6. Perspectiva feminista. 7. Conclusión. 8. Referencias bibliográficas.

Como citar: Thompson, J. P. (2017): "Nostalgia en clave positiva y perspectiva feminista: la Segunda República como hoja de ruta en Tres tiempos y la esperanza", Madrygal. Revista de Estudios Gallegos 20, pp. 215-230.

\section{Introducción}

Con todos sus defectos y limitaciones, la ficción narrativa que se ha ocupado de la memoria histórica ha tenido un papel esencial en la elaboración del trauma que provocó el fascismo en España. Su capacidad de ir más allá de la historiografía, de permitir al lector experimentar, o "vivir", la Historia, hace que sea un instrumento pedagógico necesario ahora y, sobre todo, para las futuras generaciones. La novela es quizá el medio más efectivo a la hora de ofrecer experiencias de inmersión en el pasado. Aparte de poseer la capacidad de transmitir objetivamente los hechos, puede inspirar emociones y sentimientos más que otras modalidades narrativas, sobre todo la historiografía. Las películas pueden también servir como herramientas de aprendizaje, pero la lectura de una novela suele ser más intensa que la visualización de un film; el lector tiene que crear sus propias imágenes a través de la palabra escrita y esta creación, o reconstrucción, conlleva un ejercicio más dinámico, heurístico y, hasta cierto punto, más libre ${ }^{2}$.

El auge de la narrativa que ahonda en la Segunda República, la Guerra Civil y el franquismo se debe principalmente a dos factores. Desde la década de 1990, cuando este subgénero se alza como uno de los preferidos por la comunidad lectora en el Estado español, los testigos directos de los eventos en cuestión (la primera generación) han ido desapareciendo. Hoy en día -2017- no quedan prácticamente personas que tengan recuerdos de la Segunda República o la Guerra Civil. Ha habido por lo tanto una urgencia en rescatar los recuerdos que se iban a perder para siempre. El boom de la memoria en torno al Holocausto, que comenzó en la década de 1970, tardó en llegar a España, pues no fue hasta el verano de 2002, durante la exhumación de Piedrafita de Babia, cuando la memoria histórica entró de lleno en los medios públicos ${ }^{3}$.

El segundo factor atañe a la marginación de la memoria. El silencio en torno a los crímenes contra la humanidad, y la amnistía de los que cometieron estos crímenes, constituyeron los componentes centrales del pacto que se realizó entre la dictadura y los partidos principales de la oposición. Las personas que participaron en los aparatos represivos no fueron destituidas, los jueces franquistas mantuvieron sus cargos y los políticos del régimen se reciclaron. Los tímidos avances conseguidos bajo el gobierno socialista de José Luis Rodríguez Zapatero fueron diezmados, desde 2012, con la victoria del Partido Popular. La derecha española no solo se resiste a condenar el franquismo, sino que subvenciona a asociaciones fascistas como La Fundación Francisco Franco. Por su parte, la posición del partido socialista, en lo que respecta la memoria histórica, no difiere substancialmente de la del $\mathrm{PP}^{4}$.

2 Para una reflexión más desarrollada de esta tesis, véase la introducción de mi ensayo As novelas da memoria: trauma e representación da Historia na Galiza contemporánea (Thompson 2009).

3 La primera exhumación científica - "los trece de Priaranza"- se realizó en el verano de 2000, pero no tuvo la repercusión mediática de la de 2002. Analizo esta cuestión en "The Civil War in Galiza, the Uncovering of the Common Graves, and Civil War Novels as Counter-Discourses of Imposed Oblivion” (Thompson 2005).

4 La lista sería demasiado larga para incluir aquí, pero podemos mencionar uno de los ejemplos más escandalosos, que fue el derribo de la plaza de toros de Badajoz, llevado a cabo (entre 2002 y 2006) por la orden del expresidente socialista de la Comunidad de Extremadura Juan Carlos Rodríguez Ibarra. Esta plaza de toros fue posiblemente el símbolo republicano más importante en España. 
Nuestro interés en la novela que analizamos en este artículo, Tres tiempos y la esperanza (1962) de María Victoria Valenzuela ${ }^{5}$, proviene de su valor documental -se trata de una autobiografía novelada- y su proyecto ideológico. Cuatro elementos centrales en este proyecto son las descripciones nostálgicas de la Segunda República, la representación del trauma provocado por el fascismo, el análisis sobre el consumismo y el fútbol durante la dictadura franquista; $y$, finalmente, la perspectiva feminista que, por un lado, recalca la violencia contra las mujeres republicanas y, por otro, rechaza cualquier esencialismo que diferencie a los hombres de las mujeres. Queremos reivindicar esta novela cuyo potencial a la hora de incidir en el pensamiento de hoy en día ha pasado, en gran medida, desapercibido por la crítica. Junto a otros autores gallegos que publicaron en castellano sobre la guerra civil, Tres tiempos se encuentra, según Claudio Rodríguez Fer, en una especie de "terra de ninguén, non reivindicada por ningún poder nin contrapoder, dos escritores absolutamente periféricos, que non están no centro de ningún sistema" (2001: 7).

La nostalgia suele ser considerada en clave negativa, como un pasado falso utilizado con fines mercantilistas o empleado por grupos antidemocráticos para hacer avanzar sus agendas ${ }^{7}$. Pero la nostalgia no tiene por qué ser necesariamente una forma de amnesia, fuente de consumismo o políticas reaccionarias; puede servir a causas democráticas como ocurre en la novela de Valenzuela. En este texto, la rememoración nostálgica de la Segunda República forja una visión ética y política que, en claro contraste con la devastación causada por el régimen franquista, da lugar a la esperanza de un futuro de paz y justicia. Los recuerdos idílicos que llenan la primera parte de la novela permanecen hasta el final, y ello ayuda a inspirar en el lector empatía hacia los ideales republicanos.

La perspectiva feminista que articula esta narración consiste, primero, en mostrar aquellos episodios de violencia contra las mujeres que no suelen aparecer en las novelas cuyas historias se desenvuelven en la Guerra Civil. Segundo, la novela rechaza, implícitamente, cualquier esencialismo que defienda la existencia de diferencias innatas entre las mujeres y los hombres. Las distinciones que pueda haber entre los dos sexos se retratan como consecuencias de la socialización. Las mujeres de izquierdas o de derechas lo son por las influencias ideológicas de la familia, la Iglesia, la Escuela y el Estado. De ahí que la novela ensalce en varias ocasiones la liberación de las mujeres que promovía el Estado republicano y los aparatos ideológicos fomentados por él, como las escuelas laicas.

\section{Una crítica negativa de la narrativa gue- rracivilista contemporánea}

Es evidente que no toda la narrativa que ahonda en los períodos en cuestión representa de un modo fidedigno los hechos y sus consecuencias. Desde la crítica marxista, David Becerra mantiene una postura pesimista sobre el rol que están desempeñando las novelas que versan sobre la Guerra Civil. Alega que la temática de este evento constituye una moda literaria, y es crítico sobre todo con las novelas que se encuadran dentro del subgénero "la nueva novela histórica", cuya característica más definitoria es un narrador que, desde el presente, investiga sobre un evento o una figura de la

5 Agradezco a Carmen Mejía por haberme propuesto escribir este artículo. Ella me presentó a María Victoria (Mariví) y facilitó la entrevista que hice a la autora el 4 de mayo de 2015. Utilizamos "Valenzuela" porque es el apellido que aparece en la portada de la novela. La autora utilizó este apellido (de su marido) en el exilio, y no comenzó a usar su apellido de familia y soltera "Villaverde" hasta años después. Por eso el apellido en la edición de la novela traducida al gallego (publicado en 2002) es "Villaverde".

6 El argumento de Rodríguez Fer precisa de una matización. Él propone que Tres tiempos, como las otras novelas publicadas por gallegos en castellano, son rechazadas tanto por el centralismo español - "intolerancia imperialista" (2001: 7)- como por lo que él llama "integrismo gallego" (Ibid.), que para Xoán González Millán sería "nacionalismo literario". Antón Figueroa apunta que al ser Tres tiempos una novela publicada en el exilio durante el franquismo, el llamado "criterio filológico" no resulta aplicable del mismo modo que lo será más tarde en el ámbito literario gallego. A ello contribuye también el hecho de que la portada de la novela sea realizada por Luís Seoane, lo cual con seguridad "dalle a autoridade e lexitímaa no campo de exilio de Buenos Aires. Non entrará no canon pero está dalgunha maneira lexitimada. O exilio posúe un certo poder lexitimador naquel tempo, naquel espazo, naquel contexto ideolóxico dunha 'literatura galega' aínda escrita en castelán, e máis aínda na medida en que un certo galeguismo do interior se afastaba da lexitimidade política do exilio" (comunicación personal del autor por correo electrónico, 25/07/2017).

7 Véanse, entre muchos otros, los estudios de Susan Stewart 1992 y David Lowenthal 1985. 
Guerra Civil. En este subgénero, que surgió a principios del siglo XXI como respuesta a la progresiva lejanía de los eventos, el proceso de reconstruir los hechos llega a tener tanta relevancia como la historia que se pesquisa ${ }^{8}$. Una de las ventajas que tiene la nueva novela histórica sobre novelas cuyas historias comienzan y acaban en la guerra o posguerra, es que crean un ciclo temporal que une la realidad del lector con la del pasado. Estas narraciones pueden brindar una especie de viaje de ida y vuelta, haciendo más relevante para el presente el conocimiento del pasado.

Pero para Becerra Mayor (2015), este subgénero presenta -al menos tal como se está haciendo- deficiencias con grandes implicaciones ideológicas. Los momentos actuales desde los cuales escribe el narrador/investigador están exentos de conflictos; el presente se representa como un momento ideal en el que todos los grandes problemas políticos han desaparecido gracias a la caída del bloque comunista (y con él los ideales izquierdistas), con el concomitante triunfo mundial del capitalismo. Los novelistas, según este crítico, buscan en el pasado de la Guerra Civil aventuras y problemas que no pueden (o más bien no quieren) buscar en el momento actual. Es más, lo que les interesa a los autores no es la Guerra Civil, sino este evento como telón de fondo "que bien podría sostenerse en otro contexto histórico" (2015: 26). Entre algunos ejemplos, menciona Recóndita Armonía de Marina Mayoral, La canción de Ruth de Marifé Santiago Bolaños y El tiempo entre costuras de María Dueñas, quien comentó en una entrevista que "no quería hacer una novela sobre la guerra civil; es solo el escenario" (apud Becerra Mayor 2015: 26). No es casualidad que varios de los autores que han publicado sobre la Guerra Civil provengan "de un tipo de novela histórica (...) definida mediante tramas construidas a partir de intrigas templarias, bíblicas o medievales, y cuyos autores parecen haber desistido una vez agotado el género y se han puesto a escribir sobre la historia del siglo 20 y la guerra civil" (Ibid. 21) ${ }^{9}$. Esta evasión del presente muestra que los autores tienen asumido que estamos en el "fin de la historia" (Ibid. 35) -expresión que acuñó Francis Fukuyama, que quiere decir que la humanidad ha alcanzado los tiempos definitivos de paz gracias a la hegemonía del capitalismo. Por tanto, esta narrativa que usa la Guerra Civil como telón de fondo "imprime la idea de que el pasado novelado ha terminado $\mathrm{y}$, por consiguiente, resulta inconcebible establecer relación alguna con él desde nuestro presente" (Ibid. 367).

Otro problema que comenta Becerra es que esta "moda" ha provocado un resurgir de literatura fascista; se han reeditado novelas como Los cipreses creen en Dios de José María Gironella y Madrid, de corte a checa de Agustín de Foxá (Ibid. 28); y han proliferado ensayos pseudohistóricos de revisionistas como Pío Moa y César Vidal. Este fenómeno, afirma el crítico, "no debe tildarse únicamente de revival fascista -que también- sino como efecto de una moda que aglutina textos literarios de todas las corrientes estéticas e ideológicas" (Ibid. 28-29). Sin embargo, lo que más le parece pernicioso a Becerra son las novelas de los autores que se consideran de izquierdas, pero que reproducen la falacia de la equidistancia y "la lógica ahistoricista y despolitizada de la Ley de Memoria Histórica" (Ibid. 37). La novela más representativa de este grupo es, posiblemente, Soldados de Salamina de Javier Cercas.

\section{De memoria comunicativa a memoria cul- tural}

Tres tiempos y la esperanza, deudora del neorrealismo de los años 1960, es un documento valioso porque saca a la luz los recuerdos de la autora, quien vivió la Segunda República, el golpe de estado y el terror subsiguiente. Tenía nueve años cuando la República se proclamó, y para 1936 sus convicciones republicanas eran sólidas. Los recuerdos, antes de plasmarse en la escritura, constituyen lo que Maurice Halbwachs (1980) llama "memoria social" o, en la terminología de Jan Assmann (1995), "memoria comunicativa", que engloba el diálogo y contacto diario entre los miembros de un grupo. Al publicar su novela autobiográfica, la autora convirtió memoria comunicativa en "memoria cultural"; es decir que cristalizó la memoria comunicativa en memoria de largo

Véase el artículo de Albert 2006, que ahonda en las circunstancias y la mecánica de la nueva novela histórica.

Los autores que cita Becerra son Julia Navarro, Luis Melero y Javier Lorenzo (Ibid. 21). 
plazo a través de la escritura. Las películas, los documentales y los archivos también son medios aptos para la transformación de memoria comunicativa en memoria cultural.

Al narrar recuerdos que contradicen la narración del vencedor, un autor-testigo pasa de ser objeto del discurso del perpetrador a ser sujeto de su propio discurso (Brison 1999: 39-40). Los recuerdos que publica Valenzuela conforman, sobre todo para la época (1962) en que se publicaron, un discurso revolucionario en contra de las mentiras fabricadas por el régimen franquista y aupadas por la historiografía oficial. Habían pasado veintitrés años desde la victoria fascista, y la generación que empezaba a tomar las riendas de la dictadura la segunda generación- había sido socializada bajo la propaganda (incluida la historiografía) oficial $^{10}$. La memoria, explica Richard Terdiman, es inherentemente contestataria, puesto que subvierte la hegemonía "a través de su capacidad de recordar y defender los discursos alternativos que los dominantes anularían y olvidarían" (1992: 20). Es importante destacar que una parte de la memoria comunicativa de la novela son recuerdos de otros. Un ejemplo especialmente impactante es cuando Juana (tía de la autora implicada) le cuenta, desde el cuartel donde está presa, sobre las torturas que sufrió un prisionero - antes de que los guardias lo mataran- en el mismo edificio: "Dejaron de oírse los golpes. Sólo continuaban aquellos horribles quejidos. No podría imaginarme qué le estarían haciendo" (Ibid. 89).

Una constante en la literatura de los autores de primera generación es la preocupación por reflejar la Historia tal como la presenciaron ${ }^{11}$. Valenzuela enfatizó esta preocupación en la entrevista que le hice (2015) y también en el epílogo de la edición de su obra traducida al gallego. En el epílogo de esta publicación, la autora también explica cuál fue su objetivo a la hora de dar a conocer sus recuerdos de la historia de la Segunda República: "Queríamos que fosen conscientes [nuestros hijos] do que fora a súa terra, dos avances que se lograran durante a República e das esperanzas de que algún día puidésemos volver" (Villaverde 2002:
226). Ella tiene claro que sin un conocimiento objetivo del pasado y, en este caso, de los logros democráticos de la Segunda República, es imposible tener una hoja de ruta para derribar la dictadura y devolver al país su democracia. Esencial en este proyecto ideológico republicano es que no permite que la destrucción de la República aniquile la capacidad de la sociedad para seguir luchando por ella. Si la esperanza fue posible durante la República, se puede volver a recuperar. Pero el primer requisito para luchar es desbancar las falacias fascistas, según las cuales la República fue un período de caos que provocó el golpe fascista. El objetivo de la autora es transmitir la gran esperanza que tenía el pueblo y que el sistema político que hizo posible esta esperanza no cayó de forma inevitable, sino por culpa de un grupo de asesinos bien organizados y con apoyo internacional; y también por la ingenuidad de los políticos republicanos, quienes no estuvieron a la altura para parar el golpe que se venía preparando desde la victoria del Frente Popular. El propio título de la novela simboliza esta hoja de ruta: cada tiempo corresponde a una etapa -primer tiempo (la República), segundo tiempo (los años de la guerra), tercer tiempo (la dictadura); y la esperanza, por su parte, solo se puede concebir y sostener a través de la rememoración de las tres etapas.

\section{Nostalgia}

Ana Acuña comenta que en Tres tiempos “[e] 1 recuerdo de la República es un recuerdo infantil, para la protagonista, al margen de las cuestiones ideológicas" (2011: 211). Aquí proponemos que el primer tiempo de la novela, que se ocupa del período de la Segunda República, constituye el meollo del proyecto ideológico de la obra y, por tanto, se trata de un recuerdo adulto. En esta parte se crean las imágenes y se establecen las claves interpretativas que prevalecerán hasta las últimas frases: "Allí quedaba la Tierra. ¡Nuestra Tierra! ¿Hasta cuándo? Cuando todos recuperemos la esperanza" (Valenzuela 1962: 152). Central en este proyecto es la visión nostálgica que empapa los recuerdos y las descripciones que

10 En esta generación sigue dominando, hasta hoy día, la ignorancia y la pasividad, como demuestran los estudios que llevaron a cabo Anna Miñarro y Teresa Morandi (2012), y Clara Valverde Gefaell (2014).

11 Véanse las reflexiones de Gómez López-Quiñones en el primer capítulo de La guerra persistente (2006). 
articulan el discurso narrativo. La nostalgia -el anhelo por lo que se perdió- sumerge al lector en el día a día del período republicano y en las emociones que los eventos provocaron en la autora. Pero el segundo y tercer tiempo también entran de lleno en el proyecto porque desempeñan, más allá de su valor como testimonio de los crímenes franquistas, la función de poner en violento contraste el franquismo con el proyecto ilustrado de la República. La brillantez en las descripciones de este período - colores fuertes, el himno de Riego, euforia, libertad, etc.- deslumbran de tal forma que no desaparecen; influyen al lector hasta el final de la obra. Los anhelos del pasado republicano perdido colocan al lector en una posición propicia para imaginarse qué habría sido España si no hubiera triunfado el fascismo.

La nostalgia se suele relacionar con el esencialismo y lo irracional. Los fascismos siempre reinventan pasados simplificados y exentos de problemas para encontrar una pureza (racial, ideológica, premoderna) utilizable en el presente. La nostalgia, bajo esta óptica negativa, es falsa memoria de un pasado manipulado (distorsionado). Sin embargo, la nostalgia no tiene por qué necesariamente ser un fenómeno reaccionario instrumentalizado para adoctrinar al pueblo y aupar las agendas totalitarias. John Su analiza la nostalgia como elemento pedagógico y ético en varias novelas anglófonas -escritas por afroamericanos, nativoamericanos, caribeños y nativos de las excolonias inglesasque se han publicado en las dos últimas décadas. Las imaginaciones nostálgicas en estas novelas crean un diálogo entre un presente lleno de decepción (represión, corrupción, alienación, etc.) y un pasado todavía no plagado de la injerencia extranjera. Este diálogo puede "destacar experiencias de sufrimiento borradas en las narrativas coloniales" (2005: 17). En esta literatura, "las fantasías de patrias perdidas o imaginadas" no se usan para falsificar la Historia, sino que producen "una forma de establecer ideales éticos que puedan ser compartidos por diversos grupos" (Ibid. 3).

La novelística de los nigerianos, Chinua Achebe y Wole Soyinka, es especialmente relevante para las observaciones que vamos a hacer sobre la función de la nostalgia en Tres tiempos. Estos autores escriben sobre el trauma que causó el colonialismo inglés y la Guerra de Biafra (1967-1970) que, como consecuencia de las tensiones tribales y étnicas que los ingleses habían generado, costó la vida a aproximadamente dos millones de nigerianos. Las comunidades perdidas que desean estos autores en sus narrativas pueden tener elementos idealistas, pero cuando se utilizan para contrastar el genocidio con tiempos anteriores de paz, pueden "re-estructurar la forma en que los individuos experimentan el pasado" (Ibid. 143). Estas sociedades anheladas no sacrifican los hechos históricos, sino que crean una perspectiva del pasado con más matices que llevan al lector a ponderar los momentos de posibilidades perdidas y también las comunidades que nunca pudieron realizarse (Ibid. 149). Como sucede también en las novelas del nativoamericano Navarre Scott Momaday y la nativoamericana Leslie Marmon Silko, solo las recreaciones nostálgicas que utilizan el pasado "para visualizar un grado de agencia en lugar de victimización pueden permitir a una comunidad ir más allá de su historia traumática e imaginar un futuro más satisfactorio" (Ibid. 148). En su análisis sobre Anthills of the Savannah, Simon Gikandi argumenta que Achebe reivindica en su novela "un sentido moral original" (apud Su 2005: 150), que la política postcolonial ha diezmado. El texto contrasta este pasado con el presente para "enfatizar la traición de la nación por sus líderes" (Ibid. 150). La novela constituye "un momento retrospectivo que trata de recuperar un pasado de promesa y contrastarlo con un presente de fracaso; en el momento postcolonial de la narración, los narradores deben contrastar el anhelo nacionalista de una forma y cultura homogénea con la fragmentación generada por la política del poder y la traición" (Ibid. 150).

Aunque utilizadas en contextos diferentes, las tesis de $\mathrm{Su}$ nos pueden dar claves para interpretar, en la novela que nos ocupa, las representaciones repletas de nostalgia de la Segunda República. Éstas pueden plasmarse como fragmentos de recuerdos, pequeñas viñetas o incluso broches de sucesos o de personas que pasaron por la vida de la autora. $\mathrm{O}$ pueden ser observaciones que se refieren, literal o metafóricamente, a la totalidad de la época. En este párrafo, todos los elementos cobran una proyección figurativa:

Pronto llegaban los exámenes. Ya los anunciaba el nerviosismo de las últimas clases de repaso, en que cada cual sacaba conclusiones de lo que le faltaba por estudiar, los apuros para reunir láminas, revisar apuntes y programas, el interés 
por averiguar quiénes eran los catedráticos encargados de cada asignatura. Sólo había actividad entre nosotros, y justamente cuando comenzaban los primeros calores. Las mañanas estaban radiantes en el amanecer de aquella primavera. Las plantas de yedra del patio del colegio habían prendido y ya empezaban a trepar. Cada cosa tenía un sentido diferente. El olfato, también despertaba al estímulo del aire del mar, que olía a sal y a algas. Los colores cambiaban. Se fueron los grises plomizos. Ahora eran verdes, azules, rojos y amarillos. El mar, el cielo, las cestas de cerezas que venían al mercado, las rosas nuevas, el sol que alguien hacía bailar en un espejito, las lanchas que salían a pescar. Todo adquiría, como por magia, nuevos matices, y nosotros por no ser menos, también vibramos en esta sinfonía de vida, de transformación. (Valenzuela 1962: 42)

Los componentes claves que hacen esta rememoración nostálgica son la simplificación y la síntesis. Por un lado, se condensa la idea de la transformación de individuos (conciencias) que promovía -y obligaba hasta cierto puntoel sistema republicano a través de la educación pública y laica. Por otro lado, están las emociones de euforia que experimenta la autora por medio de su aprendizaje. Las ilusiones de poder crecer, como las plantas nutridas por el sol, despiertan probablemente empatía en el lector hacia esa historia sintetizada y colectiva (todos y todas participan del proyecto) de la Segunda República. Es más, la dimensión ambigua de estas rememoraciones hace posible que puedan encajarse en las experiencias particulares de una gran parte de los que vivieron este período.

Reivindicar un sistema democrático -en este contexto la Segunda República- conlleva necesariamente tomar partido y cerrar filas, lo que implica a su vez asumir las contradicciones y los defectos del sistema (o bando) que se apoya. Es por esto que esta simplificación, y otras en la novela, no engañan al lector con información falsa. Además, las representaciones de los logros sociales y económicos de la
Segunda República (así como de las atrocidades cometidas por los franquistas) son acertadas como lo demuestran los estudios historiográficos y también la historia oral ${ }^{12}$. Se podría argumentar que la condensación narrativa de un período histórico es necesaria, en mayor o menor medida, para crear imágenes tangibles que simbolicen el Bueno y el Malo. Estas imágenes pueden, entre otras cosas, inspirar lazos emocionales hacia los que defendieron la democracia, y pueden también estimular a los lectores a seguir nutriendo sus perspectivas a través de su implicación con el pasado.

\section{La nostalgia intensificada por el trauma y la desesperación}

La visión nostálgica que emana del primer tiempo de la novela no desaparece en los siguientes dos tiempos que relatan los crímenes cometidos por el régimen franquista -segundo tiempo-, el hambre, la represión y la degradación de la sociedad civil (tercer tiempo). Tiene un peso considerable, en la lectura, el primary effect (el efecto primario) explicado por Shlomith Rimmon-Kenan (2002). La naturaliza lineal de una narración da lugar a que el emplazamiento de ciertos elementos antes que otros "puede dirigir y controlar la comprensión y las actitudes del lector" (2002: 121). La información inicial en el "proceso de percepción" (Ibid. 121) suele animar al lector a interpretar el resto del texto a la luz de esa información. Con todo, las narraciones en general tienden a "introducir un mecanismo" para que el lector modifique, al final de la lectura, sus impresiones iniciales. Este fenómeno es el recency effect (el efecto reciente), que lleva al lector a asimilar toda la previa información de la narración dentro de la perspectiva final.

El primer tiempo constituye en Tres tiempos el núcleo del proyecto ideológico de la novela, pero la nostalgia que puede sentir el lector por la República perdida no sería tan intensa si no fuera por la narración de trauma que domina el segundo y tercer tiempos. De hecho, es gracias,

12 Para un análisis de la historiografía gallega que se ha centrado en crear una crónica científica de la Segunda República y el franquismo, véase Velasco Souto 2011. En cuanto a historia oral, véase, entre otros documentales, Aillados de Antón Caeiro (2001 [1988]). El proyecto HISTORGA también recogió valiosos testimonios orales que están a disposición del público, aunque con acceso mucho más limitado desde que el PPdeG volvió al poder en 2009, anulando todas las subvenciones que había creado el gobierno bipartito (2005-2009). 
en gran medida, a esta retroalimentación entre el primary effect y el recency effect que esta novela consigue su objetivo de utilizar el pasado para forjar una conciencia política revolucionaria en el presente. Y este presente continúa porque la realidad española que la narradora nos presenta en el tercer tiempo -entre finales de 1940 y principios de 1960 - tiene muchas semejanzas con la sociedad actual. La desmemoria, el pasotismo, la degradación de la cultura y la política -que suelen caracterizar la época posfranquista- son fenómenos gestados e impuestos por la dictadura. Una vez acabados los Años del Hambre, la dictadura utilizó algunos de los mecanismos propagandísticos que están hoy al servicio de los poderes fácticos.

Más allá del shock que produce la representación -en el segundo tiempo-de las violaciones de derechos humanos, el elemento de esta parte que aumenta la sensación de pérdida son las repetidas alusiones a la incompetencia de las autoridades republicanas (con Casares Quiroga a la cabeza), que pudieron haber sofocado la rebelión, en Galicia al menos. La autora llegó a presenciar mítines, en el momento del golpe, en los que el tema central era la gran preocupación por la ingenuidad del gobierno, desde Casares Quiroga pasando por los gobernadores civiles y los alcaldes, que se negaron a distribuir armas a los sindicatos: "Todo el mundo opinaba que el gobierno se dejaba estar, que no actuaba con energía" (Valenzuela 1962: 66). La novela señala que la República no tuvo que acabar como acabó, pues la adhesión (tanto de las autoridades como del pueblo) a ella era fuerte, y que era posible parar la victoria fascista en Galicia, "la despensa y criadero" de los fascistas durante la guerra, en palabras de Cabanellas.
El tercer tiempo narra cronológicamente (aunque no totalmente) el exilio de la autora en Francia y su vuelta a España hasta que ella y su marido deciden marcharse a Argentina. Éste es el tiempo más corto de la novela a pesar de que cubre una extensión temporal más grande, desde 1937 hasta el principio del desarrollismo. Hay por tanto una mayor condensación de eventos que, sin embargo, no disminuye su impacto y relevancia en la crónica histórica que acomete la narración. El papel crucial aquí en el proyecto ideológico de la novela es poner de manifiesto las consecuencias que tuvo la victoria de Franco. Es por ello que el período de la estancia en Francia pasa a un segundo plano $^{13}$. Al principio de esta parte, cuando la autora vuelve a Galicia y se reencuentra con su marido, describe el hambre que la dictadura utilizó, entre otras cosas, para distraer al pueb$10^{14}$. La represión, como elemento indisociable de la propaganda, está siempre presente. La narradora trae a colación la detención del amigo Lemos, a quien la Guardia Civil encarcela por vender bonos del Socorro Rojo, que en realidad "sólo existían en la imaginación de las autoridades y era un pretexto que utilizaban, de tanto en tanto, cuando querían dejar bien sentado su régimen de temor. Era preciso que nadie creyera que aflojaban, que no se hicieran ilusiones" (Ibid. 139) ${ }^{15}$.

En lo que concierne al último tramo de la narración, que ahonda en los años del desarrollismo, es importante señalar que la autora no fue testigo de los acontecimientos que narra, ya que ella volvió al exilio (en Argentina) en 1949, cuando todavía no habían concluido los "Años del hambre"16. Se puede afirmar, por lo tanto, que la novela deja de ser autobiográfica en las siete páginas finales; y no es en balde

13 De hecho, la prospección de los dos primeros párrafos del tercer tiempo -en los que la autora, a finales de los 1940, llega a Bilbao para coger el tren para Galicia- sugiere que lo esencial en esta parte de la obra es lo que ocurre en España.

14 "[E]l problema de la subsistencia era tan importante para la mayoría, que absorbía todos sus esfuerzos. A excepción de los que contaban con grandes recursos económicos, o los que tenían suministros del Estado, o los que ocupaban cargos sindicales, nombrados naturalmente por la falange, los demás vivían obsesionados ante la imposibilidad de adquirir alimentos a los precios de estraperlo (...) La gente por lo general trabajaba doce o catorce horas diarias y a veces aún más (...) Todas estas preocupaciones eran las culpables de que las gentes no pudieran tener su imaginación en otra cosa" (Ibid. 132-33).

15 En esta etapa del hambre, constata también la situación de las escuelas y el profesor que cierra la suya y utiliza a sus alumnos como mano de obra para trabajar sus campos. Cuando lo descubre el inspector en el campo con sus estudiantes, el profesor le cuenta que su primera obligación es dar de comer a su familia. El inspector "no dio parte de estas irregularidades y todo continuó como estaba" (Ibid. 143).

16 Para una biografía de la autora, véase Navas Sánchez-Élez 2011. 
que esta parte de la obra sea la más analítica. Las reflexiones sobre el consumismo ${ }^{17}$ y el fútbol son especialmente relevantes, puesto que estas distracciones siguen siendo nodulares en el adoctrinamiento de la sociedad actual. El segundo como "opio del pueblo" tuvo/tiene una función determinante a la hora de borrar la memoria histórica:

Cualquiera podía ser el interlocutor ocasional, no importaba ya su conducta, ni su matiz político anterior, bastaba solo que fuera un aficionado de corazón, que se volcara por el éxito del equipo. El regreso solía ser triunfal si la suerte se había mostrado generosa, y entonces había que celebrarlo como Dios manda, en el bar o en la taberna, reunidos en franca camaradería no importa con quién, por primera vez, el perseguidor y el perseguido. (Ibid. 146)

Haciendo tangible la continuidad parcial del franquismo hasta nuestros días, la novela consigue así conectar pasado y presente sin que haya dos espacios temporales, como en la nueva novela histórica. Esta conexión logra, a su vez, que la nostalgia que acompaña al lector hasta el final del texto intervenga en el pensamiento sobre las clases dominantes de la sociedad contemporánea, que heredaron los mecanismos manipuladores de la dictadura. En otras palabras, el rechazo que promueve la narración en contra de la dictadura se puede convertir en un repudio del sistema actual, que sigue reconociendo la legitimidad del franquismo.

\section{Perspectiva feminista}

Como es de suponer, la mayoría de los autores que han escrito sobre la Segunda República, la Guerra Civil y el franquismo son hombres, lo cual presenta un problema para crear una crónica completa de los eventos, las figuras involucradas y las experiencias individuales. Dado que la perspectiva dominante en las novelas, autobiografías, historiografía y otros géneros es masculina, resulta imprescindible, por un lado, leer a contrapelo las obras de los hombres para intentar localizar posibles voces silenciadas y, por otro, reivindicar obras como Tres tiempos y la esperanza que se han quedado fuera del canon a pesar de representar verídicamente los episodios históricos y contar una historia con praxis; es decir, ofrecer al lector una hoja de ruta ideológica y práctica para transformar la sociedad actual regida por el neoliberalismo. Es más, los episodios narrados aportan información nueva al gran récit que se está haciendo sobre la Segunda República y el franquismo.

La estudiosa de literatura sobre el Holocausto, Sara Horowitz, analiza el cómic Maus que recrea las experiencias de los padres del autor Art Spiegelman, que sobrevivieron al genocidio nazi. La obra sigue el testimonio oral que el padre Vladek le confió al autor, y por tanto las experiencias de la madre Anja están filtradas por el padre y el hijo. La voz de Anja no entra en la narración, primero, porque se suicidó años antes de la preparación del libro; segundo, el padre quemó el diario de ella después de su suicidio. Los diarios desaparecidos de Anja, que "pueden servir para ilustrar la marginalidad de la experiencia de las mujeres en la construcción de una gran narración sobre el genocidio nazi" (Horowitz 2004: 111), demuestran que el análisis de género es necesario para estudiar y enseñar representaciones del Holocausto (Ibid. 112). Mientras Vladek representa a Anja como "sensible, cariñosa, emocionalmente frágil y completamente dependiente de su marido para sobrevivir", para el autor el amor maternal de la madre es "dominante e inconstante, ahogándolo con una necesidad emocional y abandonándolo a través del suicidio" (Ibid. 111).

Sin embargo, el lector de Maus puede formar otra idea de Anja, opuesta a la que transmiten el padre y el hijo, gracias a fragmentos de información que emanan del testimonio de Vladek. Por ejemplo, el padre comenta que ella trabajó para la resistencia comunista, pero una vez que él descubrió esta actividad, se la

17 "Había crecido entre la mayoría un irónico escepticismo. Ya no se creía, ya no se esperaba nada. Se estaba seguro de que nada iba a cambiar (...) Era preciso renunciar a las utopías (...) [Cada uno] quería dar fe de sus posibilidades dentro de aquel estado de cosas, quería entregarse a algo que absorbiera su capacidad mental, que colmara en cierta medida sus ansias, que le hiciera sentirse fuerte, a pesar de su debilidad, que le diera ocasión de mandar, ya que hasta entonces sólo había tenido oportunidad de obedecer, quería ser dueño aunque en su fuero interno se considerase esclavo; y entonces surgió el afán desmedido de ganar dinero" (Valenzuela 1962: 145-46). 
prohibió. Vladek le cuenta a Art que ella era una buena chica y cesó esta actividad (Ibid. 112). Destaca Horowitz que esta parte de la historia de Anja revela que ella, más allá de su supervivencia, estaba involucrada en una causa mucho más amplia (Ibid.); es decir, que mientras "Vladek protege a su familia, Anja pone su vida en peligro para el bienestar de extraños" (Ibid.). Horowitz se pregunta si Anja fue en realidad "una buena chica" que dejó sus actividades subversivas (Ibid.). Lo que está en juego, según Horowitz, es que la ausencia de la voz de Anja no solo elimina una perspectiva femenina, sino también un pasado desconocido (Ibid. 111). Es más, la narración acaba representando a Vladek como el padre protector que no pudo ser, ya que los nazis le mataron al hijo más pequeño (Ibid. 112), y como para compensar esta deficiencia, la narración le brinda una "versión hiperbólica de heroísmo de marido" (Ibid.).

Nuestro análisis, que concuerda con la óptica de Horowitz, se va a centrar en los aspectos más representativos de Tres tiempos que forjan una visión feminista acorde con los postulados del feminismo de la segunda ola. El precepto fundamental de esta corriente de feminismo es la consideración del sexo y género como producto social, como heterodesignación articulada a través de binarios; el hombre es público, activo, agresivo, racional, etc. mientras la mujer es clasificada como privada, pasiva, dulce, irracional, etc. Uno de los objetivos centrales de este pensamiento y activismo es eliminar los binarios que sirven al patriarcado para mantener su dominio sobre la mujer. El feminismo cultural (o de la diferencia) defiende que hay una diferencia innata entre hombres y mujeres; y su objetivo es reivindicar la esencia de la mujer, que es inherentemente buena. Esta línea de feminismo concibe la opresión sobre la mujer como biológica y no política. La teórica feminista María Xosé Queizán critica el esencialismo ensalzado por el feminismo de la diferencia: "Trátase de valorar o feminino sen cuestionar of feminino" (Racionalismo 29). Según Queizán, este pensamiento trata de "corrixir as inxustizas mais sen alterar o statu quo nin molestar a solidariedade entre mulleres e homes" (2004: 29). De ahí que esta corriente se dedique a "desvelar os poderes ancestrais das mulleres, ocultos pola ciencia masculina e fan referencia ás deusas nais ou a matriarcados orixinais, nun intento de re-coñecer, re-valorar o propio. O fundamental é non ser coma homes" (Ibid.).

Un estudio que -aplicado a la literatura de la guerra civil española- parte de los preceptos del feminismo de la diferencia, es el artículo de Ángela Ena Bordonada, publicado en el libro Memoria de la guerra civil en las escritoras españolas (2010). Voy a centrarme brevemente en el planteamiento de este artículo porque, al estar en las antípodas ideológicas de nuestro análisis, nos puede servir como contraejemplo del enfoque y metodología que empleamos. Ena Bordonada anuncia al principio de su texto que su intención es "observar la huella que deja la guerra española de 1936 en los escritos, de diversa naturaleza, de unas mujeres españolas que la vivieron, algunas en sus más dramáticas circunstancias" (2010: 13). La autora se ocupa de novelas de escritoras fascistas y republicanas porque, según ella, "es el único modo de obtener una visión global, confrontando las dos lecturas desde ideologías, posturas y circunstancias trágicamente enfrentadas en el plano político social y humano" (Ibid.). Algunas de las autoras fueron perdedoras, otras fueron ganadoras, "pero todas, republicanas y franquistas, hicieron uso de unos registros comunes de la memoria literaria, en cuanto que todas proyectaron sobre los hechos vividos y recordados su 'mirada de mujer"” (Ibid.).

La premisa medular de la reflexión de Ena Bordonada es que, más allá de que unas defendieron la democracia y otras el fascismo, compartieron mucho porque eran mujeres. Las causas y las consecuencias de la guerra civil le importan bien poco a esta crítica. Lo que hace falta, sugiere este discurso, es destilar la esencia de la mujer, que resolverá todo. $\mathrm{Su}$ selección de palabras no debe pasar inadvertida; por ejemplo, cuando se refiere a las autoras (republicanas y fascistas) que acabaron "trágicamente enfrentadas", la idea que transmite es que ni unas ni otras quisieron la guerra, que la autora califica con adjetivos ambiguos: "trágica", "dramática", "horrorosa", "triste"; o cuando alude a las extranjeras que fueron a España para ayudar a la República, reproduce la falacia de la equidistancia al afirmar que lo hicieron "para difundir al mundo los horrores de esta guerra" (Ibid. 15). La Guerra Civil, desde el prisma de Ena Bordonada, ocurrió como puede acaecer un terremoto. Se trata de 
tragedias que no tienen explicación política, pues dependen de fuerzas mayores ${ }^{18}$.

El discurso de esta investigadora convierte a las víctimas republicanas en fantasmas; un ejemplo particularmente llamativo de esta borradura de memoria se encuentra en sus comentarios sobre las autoras fascistas, María Sepúlveda y Concha Espina, quienes hablan en sus novelas sobre las transmisiones de Queipo de Llano. La primera escribe: “¿Oían bien la Radio Nacional? ¿Las charlas del general Queipo de Llano? ¿Qué idea tenían de cuál era la situación en la zona liberada?" (apud Ena Boronada 2010: 20). Sobre este pasaje, la investigadora hace la siguiente observación: "Aquí se refiere a las charlas del General Queipo de Llano que, desde el mismo 18 de julio de 1936 hasta febrero del 38, emite desde Radio Sevilla para crear confianza en 'los rebeldes' e inquietud en los 'leales', difundiendo frecuentes infundios" (Ibid.). Espina escribe: "Las radios populares vociferan miles de improperios contra los Jefes nacionales, especialmente contra el milagroso Queipo de Llano y sus charlas ya célebres del micrófono, que con tanto donaire difunden nuestras verdades" (Ibid.). Ena Bordonada no comenta la sustancia ideológica de estas citas ni constata que Queipo de Llano fue notorio por sus llamadas a violar a las mujeres republicanas, siendo ésta tal vez su más famosa:

Nuestros valientes legionarios y regulares han demostrado a los rojos cobardes lo que significa ser hombres de verdad y de paso también a sus mujeres. Esto está totalmente justificado porque estas comunistas y anarquistas predican el amor libre. Ahora por lo menos sabrán lo que son hombres de verdad y no milicianos maricones. No se van a librar por mucho que berreen y pataleen $^{19}$.

¿Por qué Ena Bordonada deja fuera este dato tan central sobre Queipo de Llano? ¿Será porque es suficiente evidencia para demostrar que las fascistas, como María Sepúlveda y
Concha Espina que fueron cómplices de esta política misógina y genocida, y las republicanas no compartían ninguna perspectiva mínimamente substancial? Esto no comporta, necesariamente, que Ena Bordonada quiera conscientemente borrar de la historia a las víctimas del franquismo, sino que su despolitización y reescritura de la Historia, de los verdugos y las víctimas, puede ser una reproducción inconsciente de la versión dominante de la Historia, fabricada por la Dictadura en los años que siguieron la Segunda Guerra Mundial, y que sigue siendo hegemónica hasta el presente. La despolitización del pasado que examina Becerra en las novelas de los últimos años (que quieren presentarse como progresistas) tiene su parangón en ensayos como éste que, usando la terminología de Becerra, vacían de significado los significantes de la Historia y borran "las huellas de la represión y de la significación histórica de los vencidos para poder ser asumidos, institucionalizados y normalizados por la democracia" (2015: 38).

Tres tiempos y la esperanza no presenta un proyecto feminista tan explícito como, por ejemplo, la novela de María Xosé Queizán, Amor de tango, cuya acción se desarrolla también en la Segunda República y el franquismo. La característica de Amor de tango que la hace ostensiblemente feminista son las frecuentes alusiones a la violencia masculina contra las mujeres, a saber, los patrones de fábricas que violan a sus empleadas. El éxito de la novela reside en el empleo de tácticas narrativas que impulsan al lector a interpretar el texto desde la perspectiva de las víctimas. Que María Victoria Valenzuela no fuera una teórica del feminismo, como Queizán, puede ser el motivo por el cual el contenido feminista de su novela no sea tan obvio. El componente principal que le da a Tres tiempos una visión feminista son los retratos de los personajes femeninos, que muestran la socialización como factor principal en su conformación ideológica. Sean de izquierdas o derechas, las mujeres en la

18 Esta selección de palabras tiene consecuencias, como destaca Anne McClintock en su estudio sobre la supresión de la memoria de las guerras imperiales que ha librado Estados Unidos (1990). "El excepcionalismo americano", afirma McClintock, "encuentra sus coartadas de violencia en la tragedia naturalizada" (1990: 821); esto es, la interpretación de "la historia como destino trágico se presta para la amnesia histórica y la negación de culpabilidad política" (Ibid.).

19 Se puede escuchar este fragmento en "Discurso radiofónico de Don Gonzalo Queipo de Llano" (https://www.youtube.com/watch?v=9weVo7tCvjc) o leer en el artículo de José A. Robert (2017). 
novela de Valenzuela son productos sociales; sus pensamientos y sus convicciones políticas provienen de las influencias de los aparatos ideológicos más potentes: la familia, la escuela y la Iglesia.

La familia de Valenzuela, burguesa ilustrada, es una autoridad liberadora que, con sus limitaciones, encamina a la autora en el librepensamiento y en la autonomía. Por una parte, la disciplina y las altas expectativas que le impone la madre para que sea música; por otra la libertad que le permite, como en el caso de la amistad no convencional con el vecino viudo quien se encariña con la autora ${ }^{20}$. El padre está casi siempre ausente, debido a sus labores políticas, pero su rol en el proyecto ideológico de la novela no es menos importante, puesto que lleva a la política los ideales republicanos de la familia. Además, su encarcelamiento marca un punto de inflexión en la perspectiva política/ética de la escritora, que tenía entonces doce años ${ }^{21}$.

De todas formas, las mujeres -sobre todo dos tías- inciden más en el desarrollo ideológico de la autora; la tía Carlota es una viuda burguesa sin educación formal y la tía Juana una maestra revolucionaria. La influencia de la primera es menos intelectual; Carlota no tiene que trabajar y pasa horas diarias limpiando la casa de modo semiobsesivo. Pero tiene convicciones sólidamente republicanas, analiza acertadamente la influencia de la derecha durante la República y padece violencia física por falangistas durante la Guerra Civil. La visión de la tía Juana es representativa de todos los maestros y maestras que quisieron crear un nuevo mundo en el marco de la República. Trabajaron para revolucionar el sistema educativo, sabiendo que esta institución era indispensable para formar conciencias democráticas. Hacia el final del Bienio Negro -la autora tiene casi catorce años- es suficientemente madura para tener conciencia política y empatizar con los valores éticos de la izquierda. Será la tía Juana su primer modelo ideológico porque, además de hablarle abiertamente sobre sus proyectos pedagógicos y sus aspiraciones políticas, incluye a la autora en su trabajo en la escuela ${ }^{22}$. Es más, Juana - constatamos antes- se convierte en testigo de las atrocidades fascistas, que transmite a Valenzuela. La narración no revela si Juana se salva o no, por tanto su destino se queda abierto. Pero también sus ideales revolucionarios; al quedarse en el aire la historia de Juana, su causa política también permanece, como esperando el día en que se pueda realizar.

El personaje de Ángela, la compañera de escuela de la autora, juega un papel importante porque su falta de convicciones políticas y posterior conformismo con la dictadura son consecuencia de su familia conservadora. Pero el elemento que hace el retrato de Ángela especialmente relevante para el proyecto ideológico de la novela, es su espíritu rebelde que, a pesar de su familia, puede manifestarse durante la etapa republicana gracias, sobre todo, a los nuevos espacios e instituciones: "Ella era más alegre y decidida que yo y en muchas cosas la que tomaba la iniciativa. Nada se le ponía por delante" (Valenzuela 1962: 40). Ángela y Valenzuela estudian en una escuela mixta y secular, y un día aquélla convence a ésta para que las dos transgredan las reglas de un colegio interno con el fin de ver a unas amigas. Cuando llega la directora, quien las echa con insultos, Ángela se ríe tanto que se orina (Ibid. 41).

La autora tiene que estudiar su primer año de bachillerato en el colegio de señoritas, que,

20 "Mi madre, mujer inteligente, nunca trató de cortar o amenguar esta relación, que ambos necesitábamos por igual. Para él, yo era la ilusión de cada día. Para mí, la de poseer por primera vez una devoción que me pertenecía por entero" (Valenzuela 1962: 14).

21 "Hasta entonces yo sabía que las cárceles eran para aquellos que cometían delitos tales como robar, por ejemplo, y estar preso, era una vergüenza terrible; pero ahora, comprendía que también había otras causas por las que podían encarcelar a uno; y entonces era casi un motivo de orgullo. Poco a poco iba entrando en el mundo de las personas mayores" (Ibid. 48).

22 "Yo escuchaba con toda atención sus explicaciones, y me ilusionaba que ella hablase conmigo de igual a igual, exponiéndome todas sus ideas y proyectos. Mi tía era galleguista, creía con entusiasmo que nuestra tierra debía despertar a un renacimiento cultural y económico. Todo esto sonaba nuevo en mis oídos, aunque estos conceptos los había oído más de una vez, nunca habían sido expresados para mí exclusivamente, y esta exclusividad, me hacía sentir responsable de que no cayeran en el vacío. Tendría que pensar con calma en aquello, que poco a poco iba prendiendo en mí" (Ibid. 55). 
al contrario del de varones con buenos profesores, "era un desastre desde el punto de vista pedagógico" (Ibid. 30). Esta realidad no les interesa a muchos de los padres cuyas hijas asisten al colegio porque "su única pretensión era, que recibieran ese pequeño bagaje necesario a las señoritas. Unos ligeros y pronto olvidados conocimientos y buenas maneras de actuar en sociedad" (Ibid. 31). El segundo año se traslada a otro colegio que empieza a admitir a chicas. Los profesores se implican a fondo en sus clases y llevan a los alumnos de excursión. Las dos páginas que describen la excursión concretizan la experiencia "sinfónica" que citamos antes. Los alumnos "vibran" en la nueva enseñanza republicana. Gracias a su tía Juana, Valenzuela empieza a entender la importancia de la educación como fuerza revolucionaria.

Pero el peligro que supone la Iglesia no tarda en aparecer. Mientras los dos primeros veranos que describe la narradora representan una especie de in crescendo de progreso colectivo, en el de 1933 comienza a haber una gran movilización de la derecha liderada por la Iglesia: "no se notaba ni alegría ni entusiasmo y mucho menos, ese espíritu de colaboración" (Ibid. 36). La narradora lleva a cabo un análisis detallado del papel que tuvieron los sacerdotes en el adoctrinamiento y la movilización de las mujeres con el fin de que votaran a las derechas. Digna de mencionar es su descripción de la fabricación frenética de crucifijos: "Las damas de derechas la ostentaban permanentemente colgada de su pecho. Y fue una industria muy productiva (...) Los había de todas las calidades, de todos los materiales, pero eso sí, lo importante era el tamaño. Cuanto más grandes, más amantes de la causa sagrada sus portadoras" (Ibid.). Las mismas damas comienzan a llevar trajes de baño que llegan hasta las rodillas (llamados "Laburus" por el sacerdote que los inventó) y luego en las elecciones de 1933 inician "una gran campaña de visitas de caridad a las familias necesitadas. Les llevaban limosnas, y a cambio les pedían el voto" (Ibid. 37). En casa, la autora presencia las conversaciones sobre esta movilización reaccionaria; el padre comenta que "como va a tener voto la mujer, hay que llevarla por donde la saben más vulnerable: por la cuestión religiosa. Yo os digo que esta gente va a conseguir desunir a las familias" (Ibid.). Carlota también opina: " ¿Qué bien supieron esos curas engatusar a las ignorantes que les dieron el voto por temor al infierno!"' (Ibid. 39).

El segmento de la novela en el que más evidente se hace "la mirada de mujer", no con el sentido esencialista que le da Ena Bordonada, sino con la óptica de Horowitz que enfatiza la pérdida de tantas historias traumáticas que padecieron las mujeres en el genocidio nazi, aparece en el segundo tiempo cuando la familia de Valenzuela empieza a recibir amenazas de los fascistas. Celebrando la caída de Toledo, los falangistas intentan asaltar la casa: "¿Qué salgan al balcón... esos rojos! (...) Si no abren les pondremos fuego" (Ibid. 85). Días después vienen a buscar a las tías Luisa y Carlota, las llevan a falange y las rapan. Como Carlota adopta una actitud desafiante, no le hacen tanto daño como a Luisa a quien, cuenta Carlota:

arrastraron hasta una silla. Ella se defendía como podía, con los puños y con los pies. "Mátenme, mátenme!", insistía. Vino un tercero y empezó a cortar. Ella, sujeta ya por los brazos, daba golpes con la cabeza, pero se la inmovilizaron también (...) Al terminar con el pelo, le marcaron en la frente, con nitrato de plata, unas letras; creo que son UHP. La dejaron al fin allí tirada, presa de un verdadero ataque de nervios. Ellos, mientras tanto, la hacían objeto de las más crueles burlas. Después me tocó el turno a mí, pero yo no iba a darles por el gusto. Me senté, lo más oronda, y les dije: "Qué bien, así me van a ahorrar por un tiempo el peluquero". (Ibid. 108-109)

Cabe mencionar también el episodio del asesinato de la madre con tres bebés. El personaje que narra este suceso es la amiga íntima de la familia, Gabriela, quien tiene una cierta relevancia en el proyecto ideológico de la narración. Analfabeta y pobre, sus condiciones materiales no le permitieron tener las mismas oportunidades que tuvo la autora, y es por ello que no llega a entender y apreciar los ideales republicanos hasta que llega el fascismo y las barbaridades. Ella, que se convierte en una fuente de historias que escucha en la calle, cuenta que los guardias civiles matan a la mujer por dar cobijo a su marido escapado: "No hubo para ella misericordia. A rastras la sacaron de la celda donde quedaban las criaturas enloquecidas, y apenas unos metros más allá la mataron" (Ibid. 101).

La visión feminista de Tres tiempos se elabora, por tanto, desde dos ángulos. Destaca, por un lado, la violencia fascista contra las mujeres, sea por su parentela con hombres 
republicanos significados -caso de las tías de la autora y la mujer del escapado- sea por su activismo izquierdista y galleguista (la tía Juana). Por otro, ejemplifica cómo la República proporcionó las condiciones -sobre todo por medio de la historia de Ángela- que permitieron a las mujeres librarse de las instituciones opresivas y la ideología patriarcal. Asimismo, a través de sus observaciones y análisis, la narradora muestra que el gran culpable de la misoginia, y el retroceso de los avances logrados durante el Bienio progresista, fue la Iglesia y su campaña propagandística que consiguió que la mayor parte de las mujeres votaran en contra de su libertad.

\section{Conclusión}

Al principio de este estudio hicimos alusión a la falta de reconocimiento por parte de la crítica de Tres tiempos y la esperanza. La recepción que tuvo la novela cuando se publicó fue positiva $^{23}$, pero la obra no entró en el canon de la narrativa española que versa sobre la Segunda República, la Guerra Civil y el franquismo. La novela fue, comentamos, legitimada en el exilio y luego rescatada por Edicións A Nosa Terra, que la tradujo al gallego y la reeditó en 2002 -queriendo incorporarla dentro del ámbito literario gallego que se rige por el criterio filológico-, pero en el espacio estatal ha sido relegada al desván de la historia ${ }^{24}$. El valor testimonial y el proyecto ideológico de la obra no son vendibles para la industria cultural que constata Becerra-saca más rendimiento de las novelas que utilizan la guerra civil como aventura, evasión del presente "aburrido", o como "telón de fondo". Hemos querido en este artículo reivindicar Tres tiempos como un texto que debería tener más visibilidad dentro de la narrativa que explora los eventos en cuestión.

Sin duda, ha influido en la marginalidad de esta novela, y de otras con planteamientos ideológicos parecidos, el "fin del comunismo" que, además de desintegrar las utopías izquierdistas y acelerar la fragmentación social y política que provoca el capitalismo tardío, también ha mermado el prestigio social de los que lucharon contra el fascismo. Explica Enzo Traverso que estos héroes de antes (los vencidos) han sido eclipsados por la figura de la víctima (2005: 16). Este protagonismo que tienen ahora las víctimas previamente ignoradas y el olvido de los héroes antes idealizados es signo, afirma el historiador italiano, del "anclaje profundo de la memoria colectiva en el presente" (Ibid. 16). Es decir, la historia de las víctimas del Holocausto, según Traverso, resulta más útil hoy día a los poderes fácticos que la historia de los que lucharon y murieron por los ideales de la izquierda. Utiliza como ejemplo la visita de Tony Blair, Silvio Berlusconi y Dick Cheney a Auschwitz, que sirvió para "enviar un mensaje reconfortante" con la intención de hacernos ver "el nazismo como legitimación en negatif del Occidente liberal como el mejor de los mundos" (Ibid. 81).

Para combatir la desmemoria, urge no solo crear espacios conmemorativos que involucren a la juventud ${ }^{25}$, sino también recuperar y divulgar los textos cuyas historias e imaginarios proponen revolucionar la sociedad actual. La ficción narrativa es sumamente efectiva (y necesaria) a la hora de transmitir el conocimiento de los eventos históricos. La ventaja principal que posee la novela, señaló Mikhail Bakhtin, es que permite la incorporación de varios géneros, tanto artísticos como extraartísticos (1981: 320 ${ }^{26}$. Puede emplear el lirismo y otros registros abiertamente subjetivos, y también discursos científicos. Desde la historiografía hay un cierto rechazo hacia las novelas y también las autobiografías que pretenden narrar y analizar la Historia. La historiografía, explica Jeremy Popkin, "adopta como su sujeto no los seres humanos individuales con sus vidas arbitrarias, sino colectividades más grandes, e inserta sus narrativas en un marco temporal más grande que, en principio, incorpora toda la experiencia humana" (2003: 50).

23 Hay cuatro reseñas de la novela (publicadas en América) que se pueden leer en Acuña 2011: 217-221.

24 Trajimos a colación -en la nota a pie de página 7- esta cuestión de la legitimación de la obra en el exilio, pero para entender esta novela en su contexto sería preciso analizarla empleando, por ejemplo, la óptica teórica utilizada por Antón Figueroa en su ensayo Ideoloxía e autonomía no campo literario galego (2010).

25 Un ejemplo es Pinta Pasado, Crea Futuro, que dirigí en la municipalidad de Fene en 2016. Elaboré un documental sobre sobre este proyecto, que se puede ver en YouTube (Thompson 2017).

26 Véase su ensayo "Discourse in the Novel", publicado en The Dialogic Imagination (1981). 
Pero los recuerdos son también Historia, y no necesariamente más subjetivos que las crónicas escritas por los historiadores, que suelen distanciarse de la memoria para intentar ser lo más objetivos posible. Traverso contrasta el tipo de información que darían, sobre unas fotos de Auschwitz, un historiador y un testigo directo:

El historiador sabe generalmente explicar lo que pasa en ellas, pero el testigo se acuerda de las sensaciones, de las emociones, de los ruidos, de las voces, de los olores, el miedo y la desorientación al llegar al campo, la fatiga de un largo viaje hecho en condiciones horribles. Dicho de otra forma, él recordará un conjunto de imágenes y de recuerdos totalmente singulares y completamente inaccesibles al historiador. (2005: 21-22)

No cabe duda de que los testimonios de primera mano - me refiero a las grabaciones de testigos oculares, las autobiografías o las novelas autobiográficas como la de Valenzuela- aportan información de la que carecen los estudios historiográficos o las novelas escritas por autores que no vivieron los acontecimientos. Incluso cuando el testigo narra una historia de segunda mano (por ejemplo, las torturas en la cárcel que le contó Juana a la autora de Tres tiempos), la cercanía (temporal y espacial) al hecho confiere una autenticidad que difícilmente puede transmitir un novelista/investigador que narra desde el presente ${ }^{27}$.

\section{Referencias bibliográficas}

Acuña Trabazo, Ana (2011): “Obra periodística de Ramón de Valenzuela y de María Victoria Vilaverde”, en C. Mejía Ruiz (coord.), Dos vidas y un exilio. Ramón Valenzuela y María Victoria Villaverde. Estudio y antología. Madrid: Editorial Complutense, pp. 80-101.

Albert, Mechthild (2006): “Oralidad y memoria en la novela memorialística", en U. Winter (coord.), Lugares de memoria de la guerra civil y el franquismo. Representaciones literarias y visuales. Madrid / Frankfurt: Iberoamericana / Vervuert, pp. 20-37.

Assmann, Jan (1995): “Collective Memory and Cultural Identity", New German Critique 65, pp. 125-133. Bakhtin, Mikhail M. (1981): The Dialogic Imagination. Austin: University of Texas Press.

Becerra Mayor, David (2015): La guerra civil como moda literaria. Madrid: Clave Intelectual.

Brison, Susan (1999): "Trauma Narratives and the Remaking of the Self”, en M. Bal, J. Crewe y L. Spitzer (eds.), Acts of Memory: Cultural Recall in the Present. Hanover: University Press of New England.

Caeiro, Antón (dir.) (2001 [1988]): Aillados. A memoria dos presos de 1936 na Illa de San Simón. Documental. Buxo Produccións.

Cercas, Javier (2001): Soldados de Salamina. Barcelona: Tusquets.

Ena Bordonada, Ángela (2010): "Escritoras", en Memoria de la guerra civil en las escritoras españolas. Madrid: SIAL, pp. 13-51.

Figueroa, Antón (2010): Ideoloxía e autonomía no campo literario galego. Santiago: Laiovento.

Gómez López-Quiñones, Antonio (2006): La guerra persistente: memoria, violencia y utopía: Representaciones contemporáneas de la guerra civil española. Madrid / Frankfurt: Iberoamericana / Vervuert.

Halbwachs, Maurice (1980): The Collective Memory. New York: Harper \& Row Publishers.

Horowitz, Sara (2004): “Gender and Holocaust Representation”, en M. Hirsch e I. Kacandes (eds.), Teaching Representation of the Holocaust. Hirsch, Marianne y Irene Kacandes. New York: The Modern Language Asssociation of America, pp. 110-122.

Lowenthal, David (1985): The Past is a Foreign Country. Cambridge: Cambridge University Press.

McClintock, Anne (1990): "Imperial Ghosting and National Tragedy: Revenants from Hiroshima and Indian Country in the War on Terror", PMLA 129/4, pp. 819-829.

27 Para una perspectiva construccionista (posmoderna) sobre la relatividad del lenguaje para transmitir realidades extra-textuales, véase James Young 1988. Reflexiono sobre la cuestión de autenticidad con respecto a las autobiografías y la ficción narrativa en el capítulo siete de As novelas da memoria (Thompson 2009). 
Miñarro, Anna y Teresa Morandi (eds.) (2012): Trauma y transmisión: Efectos de la guerra del 36, la posguerra, la dictadura y la transición en la subjetividad de los ciudadanos. Barcelona: Fundació CCSM / Xoroi Edicions.

Navas Sánchez-Élez, María Victoria (2011): "Ramón de Valenzuela (1914-1980) y maría Victoria Villaverde (1922-): un viaje de idea y vuelta", en C. Mejía Ruiz (coord.), Dos vidas y un exilio. Ramón Valenzuela y María Victoria Villaverde. Estudio y antología. Madrid: Editorial Complutense, pp. 25-77.

Popkin, Jeremy (2003): "Holocaust Memories, Historians' Memoirs: First-Person Narrative and the Memory of the Holocaust", History and Memory 15/1, pp. 49-84.

Queizán, María Xosé (1992): Amor de tango. Vigo: Xerais. (2004): Racionalismo político e literario: Conciliar as ciencias e as humanidades. Vigo: Xerais.

Rimmon-Kenan, Shlomith $\left(2002^{2}\right)$ : Narrative Fiction. Londres / Nueva York: Routledge.

Robert, José A. (2017): "Las rapadas que nunca deberíamos olvidar", Instituto Martha Zerbini 19/05/2017 (http://institutomz.com/nuevo/2013-09-20-18-23-11/coordinador-general-del-instituto-mz/ 3876-las-rapadas-que-nunca-deberiamos-olvidar).

Rodríguez Fer, Claudio (2001): "Prólogo", en S. Carbalido Reboredo, Novela en pé de guerra: A guerra civil vista polos novelistas galegos en castelán. Sada: Ediciós do Castro, pp. 7-8.

Stewart, Susan (1992): On Longing: Narratives of the Miniature, the Gigantic, the Souvenir, the Collection. Durham: Duke University Press.

Su, John J. (2005): Ethics and Nostalgia in the Contemporary Novel. Nueva York: Cambridge University Press.

Terdiman, Richard (1992): Present Past: Modernity and the Memory Crisis. Ithaca: Cornell University Press.

Thompson, John Patrick (2005): "The Civil War in Galiza, the Uncovering of the Common Graves, and Civil War Novels as Counter-Discourses of Imposed Oblivion”, Iberoamericana 18, pp. 75-82.

(2009): As novelas da memoria: trauma e representación da historia na Galiza contemporânea. Vigo: Galaxia.

- (2017): Pinta Pasado, Crea Futuro (editado por C. Tash). Documental (https://www.youtube.com/ watch? $=$ iPhQe_fmgt4).

Traveso, Enzo (2005): Le passé, modes d'emploi: histoire, mémoire, politique. París: La frabrique éditions.

Velasco Souto, Carlos (2011): "Repressom franquista e memoria histórica na Galiza. Historiografia e linhas de pesquisa fundamentais", Murguía. Revista galega de historia 23-24, pp. 73-96.

Valverde Gefaell, Clara (2014): Desenterrar las palabras: Transmisión generacional del trauma de la violencia política del siglo XX en el Estado español. Barcelona: Icaria.

Valenzuela, María Victoria (1962): Tres tiempos y la esperanza. Buenos Aires: Editorial Alborada.

Villaverde, María Victoria (2002): "Palabras que escribín corenta anos despois", en Tres tempos e a esperanza. Vigo: A Nosa Terra, pp. 225-241

Young, James (1988): Writing and Rewriting the Holocaust: Narrative and the Consequences of Interpretation. Bloomington / Indianapolis: Indiana University Press. 